\title{
Clinical Case Reports: Scar Prevention by Laser Treatment in Mastopexy With Implant
}

Vincent Hunsinger, Martin Lhuaire, Ibrahim Dagher, and Laurent Lantieri

\section{Contents}

59.1 Introduction $\mathbf{- 5 1 0}$

59.2 Case Report Number $1-511$

59.3 Case Report Number 2 - 513

59.4 Discussion $-\mathbf{5 1 3}$

References -515 


\subsection{Introduction}

Breast ptosis is one of the most common conditions treated by plastic surgeons with more than 100,000 operations each year just in the USA. While its causes are not clearly defined, age, history of significant weight loss, higher body mass index (BMI), larger bra cup size, the number of pregnancies, and smoking history are known to be significant risk factors [1]. Treatment consists generally in mastopexy and/or breast augmentation with implant fitting. The mastopexy procedure is generally considered a reliable aesthetic procedure with less than $2 \%$ of unsatisfactory breast shape [2]. In addition to operative risks related to any surgery performed under anesthesia, some complications specific to breast plasty and breast implant may occur such as hematoma, infection, wound healing delay, wound dehiscence, necrosis of the areola, necrosis of the skin, disruption of the implant and silicon leakage, rare case of anaplastic large cell lymphoma, and poor quality of the scars, including hypertrophic scar or keloid [1]. The overall complication rate of mastopexy reaches $10 \%$ and the most represented complications are scar related, with $3 \%$ of hypertrophic or unaesthetic appearance [2]. The patients' perspective is also essential when evaluating scar cosmetic appearance as it might differ from the ones of the surgeon $[3,4]$. In particular, their expectations at short term (inflammatory stage) and long term (1 year) are of equal importance as they usually wish to regain a normal appearance skin as soon as possible and desire sustainable results $[3,4]$. To minimize the aesthetic impact of surgical scars, many different strategies have been identified, such as compressing devices, sun protection, silicone dressing, or laser treatment $[5,6]$. According to the recent guidelines, prevention of abnormal scar formation should always be a first priority [5-7]. Preventive measures adapted to the patients' risks and needs (possibly including combined therapies) and early intervention are well recognized for their positive outcomes [5-7]. In particular, laser therapy seems to gain each year broader and broader application in this field [8]. Ten years ago, a new approach based on a preventive treatment of scars called Laser-Assisted Skin Healing (LASH) was developed by Pr Mordon (INSERM U703; University of Lille Nord, France), and clinically evaluated by the teams of Pr Magalon (Department of Plastic and Reconstructive Surgery, APHM, Marseille, France) and Dr. Capon (Plastic and Reconstructive Surgery Department of Pr Martinot and Pellerin, CHRU, Lille, France) [9]. Performed immediately after surgery, a laser shot induces a controlled elevation of skin temperature, which activates the overexpression of chaperone proteins (Heat Shock Protein 70) $[9,10]$. These proteins then activate tissue regeneration by shortening the inflammatory stage of the wound healing process and hasten scar maturation [9]. This technique, performed during the earliest stage of the healing process for a maximum impact, gave promising results. In 2016, a new laser system was marketed on the basis of this LASH technique. The 1210-nm laser diode (UrgoTouch ${ }^{\circledR}$, Laboratoires Urgo Medical, Chenove, France) was an automated, portable laser providing a controlled elevation of skin temperature, due to its scar control system technology. The wavelength of the system allows its use on patients with all skin phototypes, including Fitzpatrick scale phototypes V and VI. The performance and safety of this new device were assessed in a 1-year follow-up doubleblinded randomized controlled trial (RCT), undertaken on patients undergoing breast reduction: The "SLASH" study [11]. This high-quality-level study was conducted in France and coordinated by Pr Casanova at the University Hospital of Marseille. A total of 40 women (with phototypes II to VI) undergoing bilateral breast reduction were enrolled by the five surgeons involved in the study and treated with the portable 1210-nm laser on one randomly assigned breast, while the controlateral one was used as the study control. The unique lasertreatment session was performed on the suture incisions, in the operating room, while the patient was still under the general anesthesia. According to the results of this clinical study, based on both subjective assessments (with the validated modified Observer Scar Assessment Scale (mOSAS) score) and objective measurements (with software analysis of three-dimensional [3D] pictures of the scars) the 1210-nm automated laser system provided significant improvements of the cosmetic aspect of the scars at short term (6 weeks), medium term (6 months), and long term (12 months) (- Fig. 59.1). These aesthetic improvements, notably in terms of volume, surface, and roughness, were strengthened with the blind expression of patients' preference for their laser-treated scars. Of note, in the subgroup of dark skin-type patients (phototypes V-VI), the results also favored the laser treatment, with $53 \%$ and $16 \%$ mean reductions of the scar volume and surface, compared to the control scars.

I have personally used this laser treatment (- Fig. 59.2) in many different indications in my current practice and I propose to report here two cases of breast hypotrophy and ptosis treated by mastopexy with implants associated with the laser treatment. 


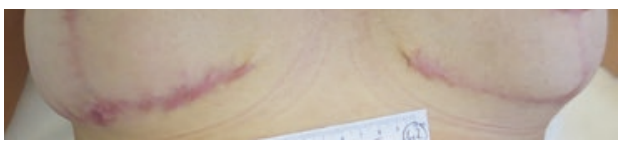

Control

Laser-treated

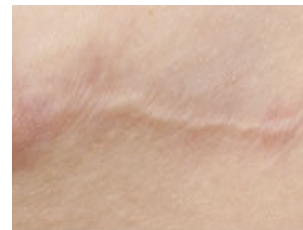

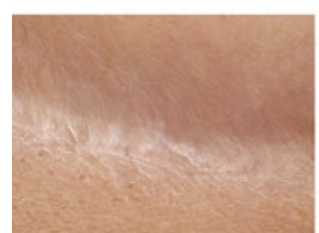

Control
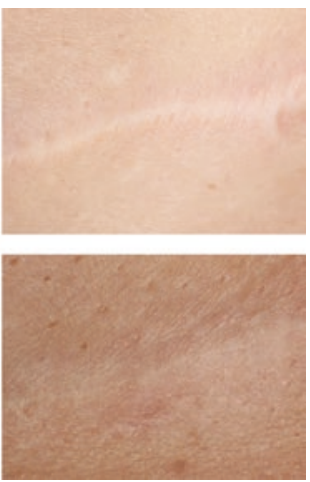

Laser-treated
- Fig. $\mathbf{5 9 . 1}$ On the left, a two-dimensional (2D) photograph of the inframammary scars of a patient, 6 months after her breastreduction procedure. The horizontal scar of one breast was randomly assigned to receive in the operating theatre, the day of the surgery, the laser treatment while the other scar of the controlateral breast was used as a control. On the right, 3D photographs of internal or external extremities of the scars treated or not with the laser in two different patients, 12 months after the procedure. (Reproduced from the double-blind RCT "SLASH" with the courtesy of Pr. Casanova, coordinator of the clinical trial)

\subsection{Case Report Number 1}

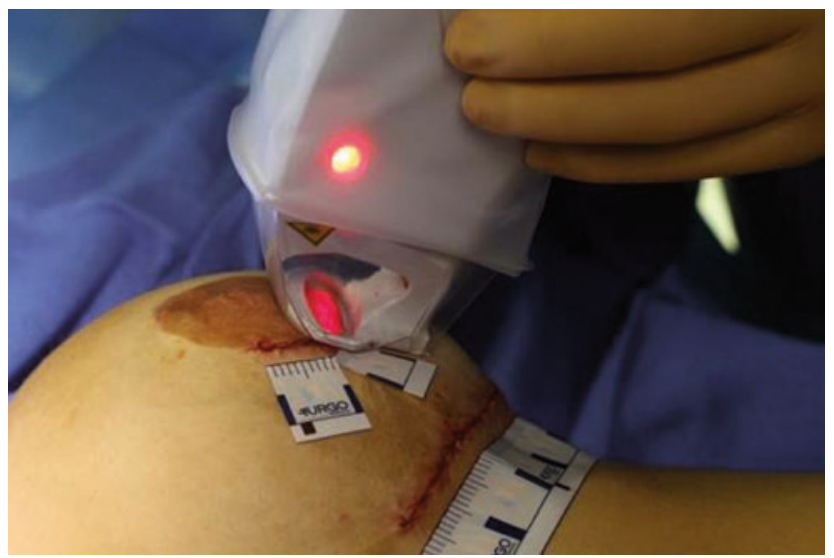

Fig. 59.2 The 1210-nm laser diode laser system UrgoTouch ${ }^{\circledR}$ procedure. The laser treatment (only one pass over the incision) is performed in the operating theatre, when patients are still under general anesthesia. The target cutaneous zone is secured by the application of safety strips containing high-technology microchips. These microchips enable the laser shots and prevent any overdose. The sterile strips are positioned along the sutures just before the laser shot. The laser shot duration is determined and controlled by the laser software itself, based on the patient's skin temperature detected by the embedded pyrometer of the device. This technology ensures the automatic discontinuation of the shot when the target skin temperature $\left(53 \pm 3^{\circ} \mathrm{C}\right)$ is reached, ensuring both patient safety and reproducibility of the shots. Neither preliminary parameter settings nor adjustments are required for laser shots. A training to the laser is received before its first use

\section{- Description}

A 37-year-old woman with bilateral breast hypotrophy and ptosis was seen in consultation seeking for breast lift. Physical examination revealed 85C-sized breasts with grade 2 ptosis based on the Regnault classification (Nipple areola complex [NAC] $2 \mathrm{~cm}$ below the submammary fold) and asymmetry (with a left breast more voluminous and ptosic than the controlateral one). The patient $(1.70 \mathrm{~m}, 58 \mathrm{~kg}, \mathrm{BMI} 20)$ had recently lost $15 \mathrm{~kg}$ and reported a previous $95 \mathrm{C}$ breast size. She had three children and no prolonged breastfeeding period. The patient had no history of surgery, allergy, or medications, but was a current smoker.

A bilateral breast lift with retropectoral implants and laser treatment was proposed to the patient. The benefits and risks related to the procedure were explained, together with the necessity to quit smoking, before the patient gave her written consent.

\section{- Methods}

The surgery was performed in November 2017, under general anesthesia and orotracheal intubation. The patient had received antibioprophylaxy and perioperative compression stockings and she underwent preoperative marking. A similar procedure was followed for both breast. Infiltration of local anesthetics (narope- 
ine $7.5 \mathrm{mg} / \mathrm{mL}+$ xylocaine/adrenaline $1 \%$ ) was done in the targeted zone. The incision on each breast was made under the future nipple-areola complex flap, with a glandular transection, until it reached the pectoralis muscle. The retropectoral area was dissected to develop the submuscular pocket at the implant size and a sizer was used for the mastopexy. The breast was lifted using inverted-T scar and a superior NAC pedicle technique. The round micro-textured breast implants prefilled with silicone gel were then placed in its pocket (LSM RM 345 , Sebbin) and the satisfying shape and volume of the breast were checked. Surgical incisions were sutured according to local standard procedures, using common surgical sutures (Monocryl ${ }^{\mathrm{TM}} 3 / 0$ and $4 / 0$ and Vicryl ${ }^{\mathrm{TM}}$ rapide $4 / 0$, Ethicon) compatible with the laser use, according to the laser manufacturer's instructions.

The safety strips of the laser were positioned along the sutured incisions. The laser shot duration was determined and controlled by the laser software itself, based on the patient's skin temperature detected by the embedded pyrometer of the device. The laser treatment procedure was rapid and went unremarkable. After the laser treatment, the sutured incisions were secured with 2-octyl cyanoacrylate adhesive (Dermabond $\AA$, Ethicon) and covered by a dry dressing, before adding the postoperative compressive bra.

Postoperative care recommendations included daily shower and dressing change after cleaning of the sutured incisions with an antiseptic solution. The patient was asked to wear postoperative compression bra for 4 weeks after the surgery and received a prescription for analgesics. Sport activity resumption was allowed 3 months after the surgery.

\section{- Results}

No complication was reported during the procedure and the early postoperative course. One month after the surgery and the laser treatment, the cosmetic aspects of the scars were already satisfying and the patient was pleased with this short-term outcome (• Fig. 59.3).
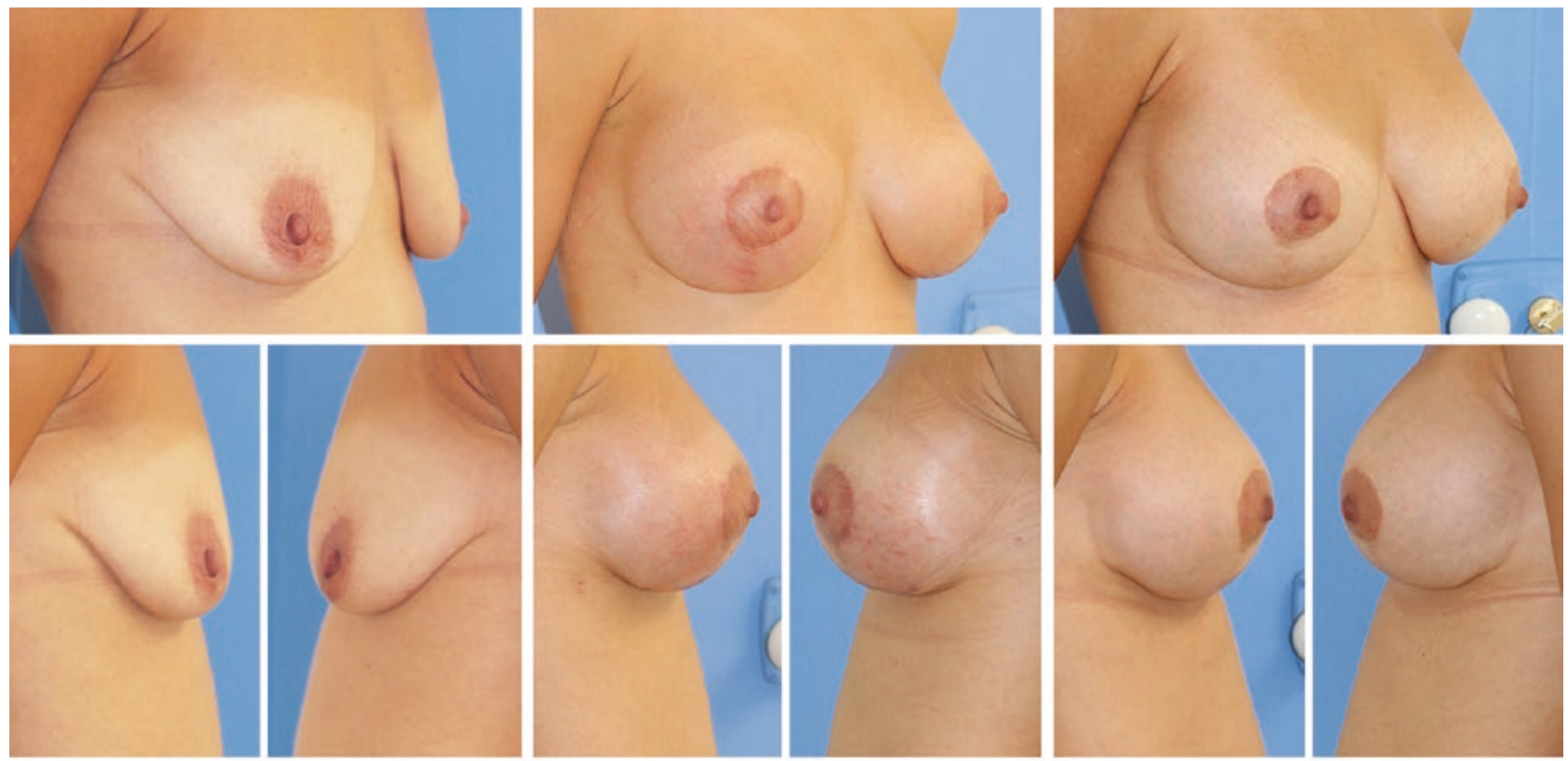

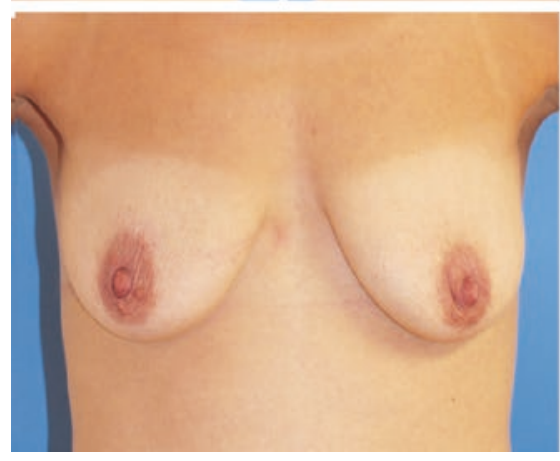

Pre-operative ptosis

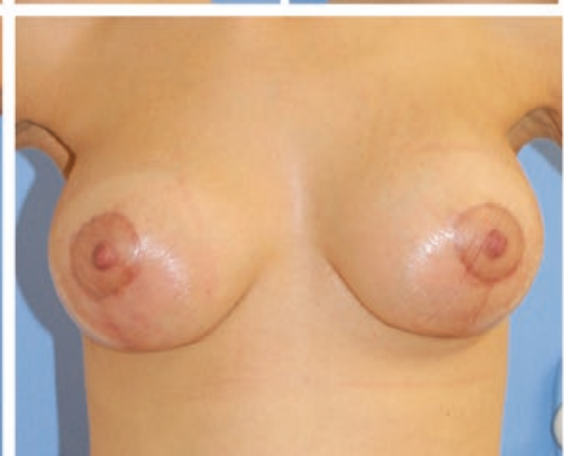

1 month

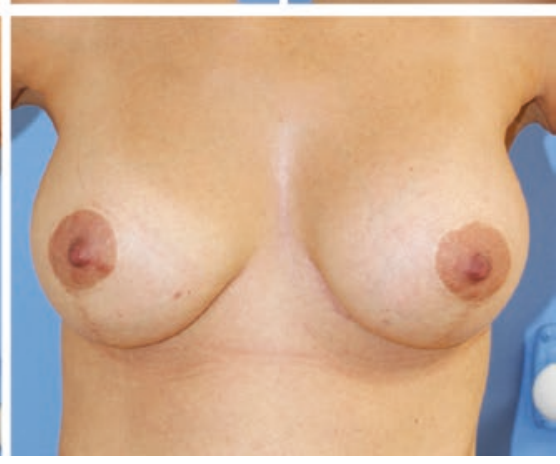

18 months

- Fig. 59.3 Eighteen months' follow-up of the patient: anterolateral, lateral, and anterior views of the preoperative ptosis and of the breasts 1 month and 18 months after the surgery and the laser treatment 

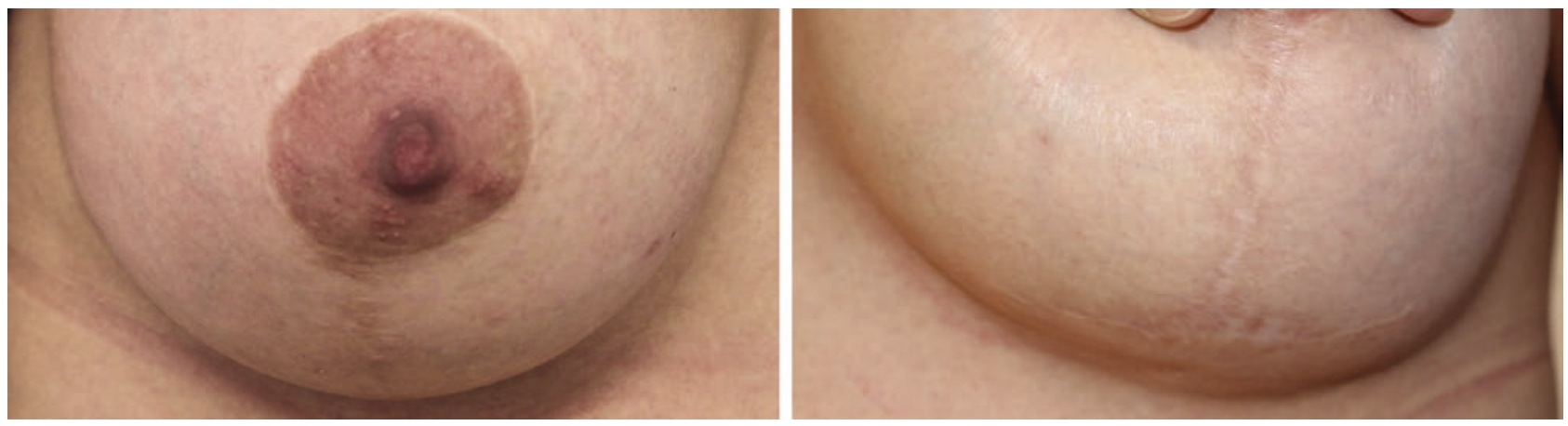

Fig. 59.4 Enlarged photographs of periareolar and vertical scars of each breast, 18 months post-surgery

At the 18-month postoperative visit, the horizontal, vertical, and periareolar scars became very discreet and the patient expressed her complete satisfaction for her new breasts (• Figs. 59.3 and 59.4).

\subsection{Case Report Number 2}

\section{- Description}

The second case report relates to a 26-year-old woman $(1.64 \mathrm{~m}, 60 \mathrm{~kg}$, BMI 22) seen in consultation for breast lifting after weight loss. The patient presented a bilateral breast hypotrophy and grade 2 ptosis (NAC $1 \mathrm{~cm}$ below the submammary fold). The breasts were asymmetric (more voluminous and ptosic left breast). The patient currently had B-cup breasts and wanted a breast augmentation to reach plain C-cups. The review of the medical and surgical history of the patient revealed a sleeve-gastrectomy in March 2013, no allergy, no particular familial medical history, and no current medications, but she was a current smoker. A bilateral breast lift with retropectoral implants and laser treatment was proposed to the patient. She was informed that she had to quit smoking and the benefits and risks related to the procedure were explained to her. The surgery was scheduled in January 2018, once the written consent of the patient was obtained.

\section{-. Methods}

The surgery was performed under general anesthesia and laryngeal mask. The procedure was globally similar to the one reported in Case 1. The glandular transection reached the pectoral muscle plan. The submuscular area was dissected to develop the implant pocket. Inverted-T incision and superior NAC pedicle technique was used and the round micro-textured breast implants prefilled with silicone gel were positioned in their pocket (LSM RS 270, Sebbin, for the right breast, and LSC 72330, Sebbin, for the left breast). The shape and volume of the breasts were checked and judged satisfying. The surgi- cal sutures and laser treatment were performed as previously described. After the laser treatment, the sutured incisions were secured with steri-strips and covered by a dry dressing, before adding the postoperative compressive bra. The global procedure (including surgery and laser treatment) lasted 2 hours. The drains were removed the day after the surgery. Postoperative care recommendations were similar to the ones given in Case 1 .

\section{- Results}

No complication was reported during the procedure and the postoperative course. Two months after the surgery, the interest of an early laser treatment on the inflammatory stage of the wound healing process was noticeable. At the 12-month postoperative visit, the scars were barely detectable. The cosmetic aspects of the scars were very satisfying and the patient was pleased with the results of the procedure, at both the short-term and long-term visits (• Figs. 59.5 and 59.6).

\subsection{Discussion}

To my knowledge, this is the first time the use of the automated 1210-nm laser diode UrgoTouch ${ }^{\circledR}$ is reported in mastopexy associated with retropectoral implant. The short- and long-term cosmetic results reached after a unique session, realized in the operating theater the day of the surgery, were very satisfying from both the surgeon' and the patient's point of view, and consistent with the results reported in the "SLASH" RCT conducted in the breast-reduction indication.

I first tried this laser treatment in October 2016 in a revision of breast and abdominoplasty in a patient of dark phototype skin presenting at my consultation with very wide scars. The aesthetic outcomes of the scars at 10 months were very satisfactory and the patient said that she was happy with the result obtained. Subsequently, I have treated the scars of more than two hundreds of patients in different indications: secondarily to breast 

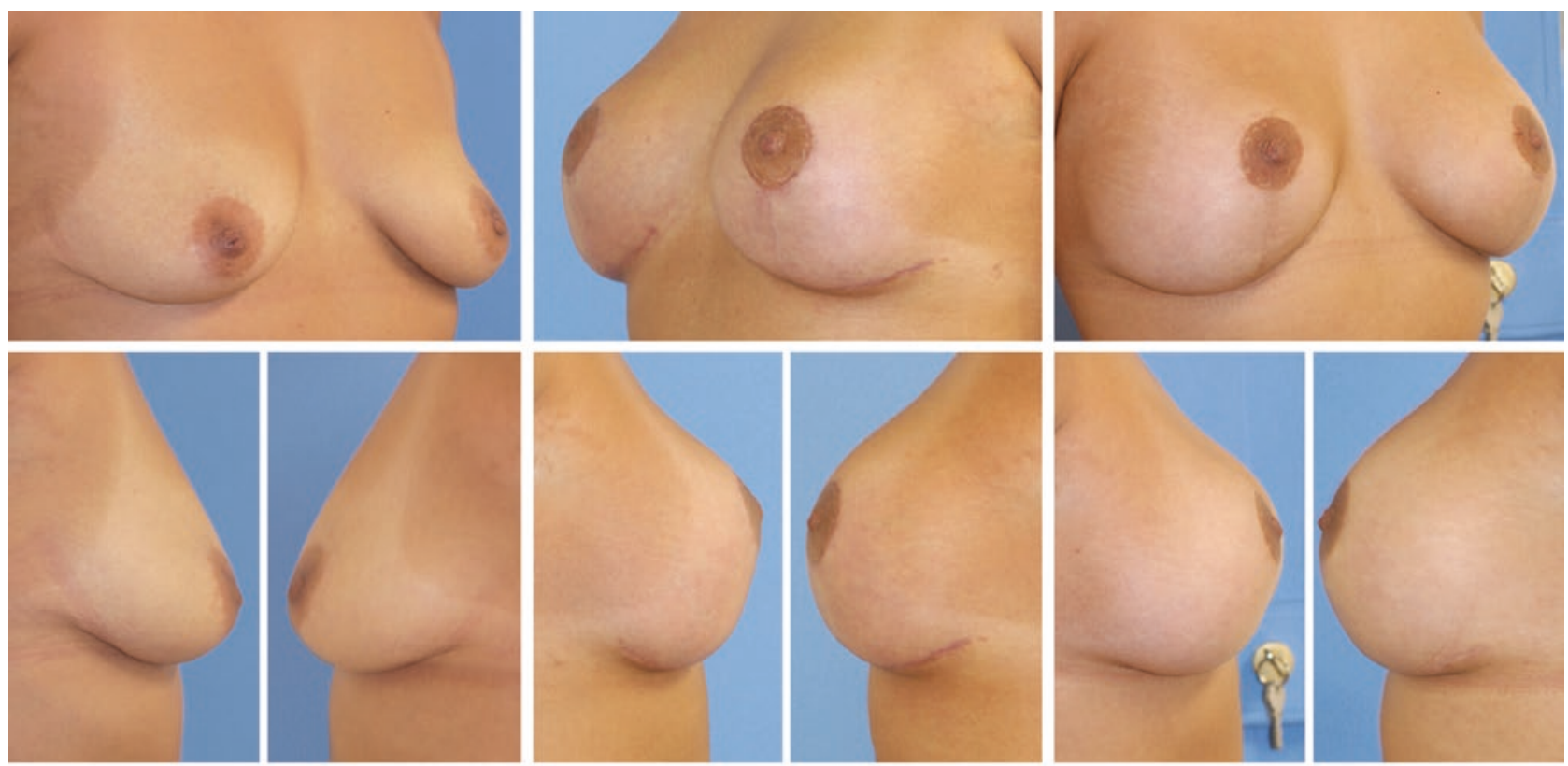

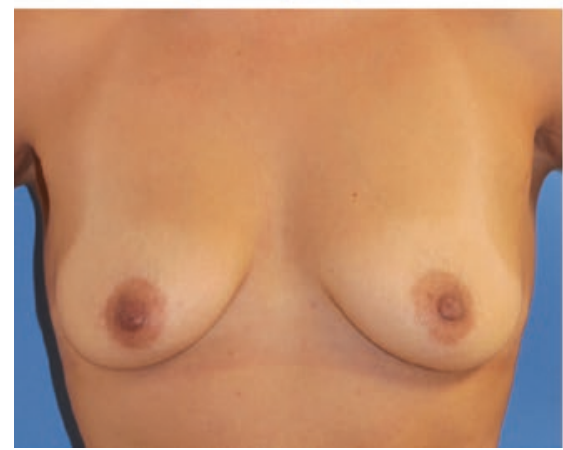

Pre-operative ptosis

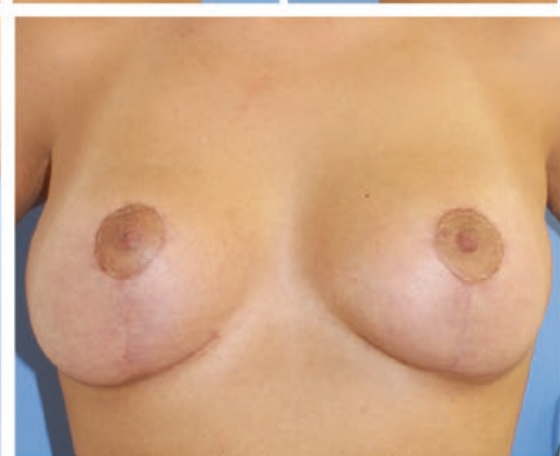

2 months

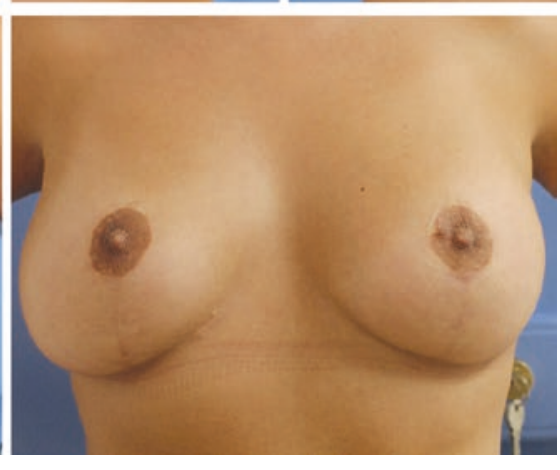

12 months

- Fig. 59.5 Twelve months' follow-up of the patient: anterolateral, lateral, and anterior views of the preoperative ptosis and of the breasts 2 months and 12 months after the surgery and the laser treatment
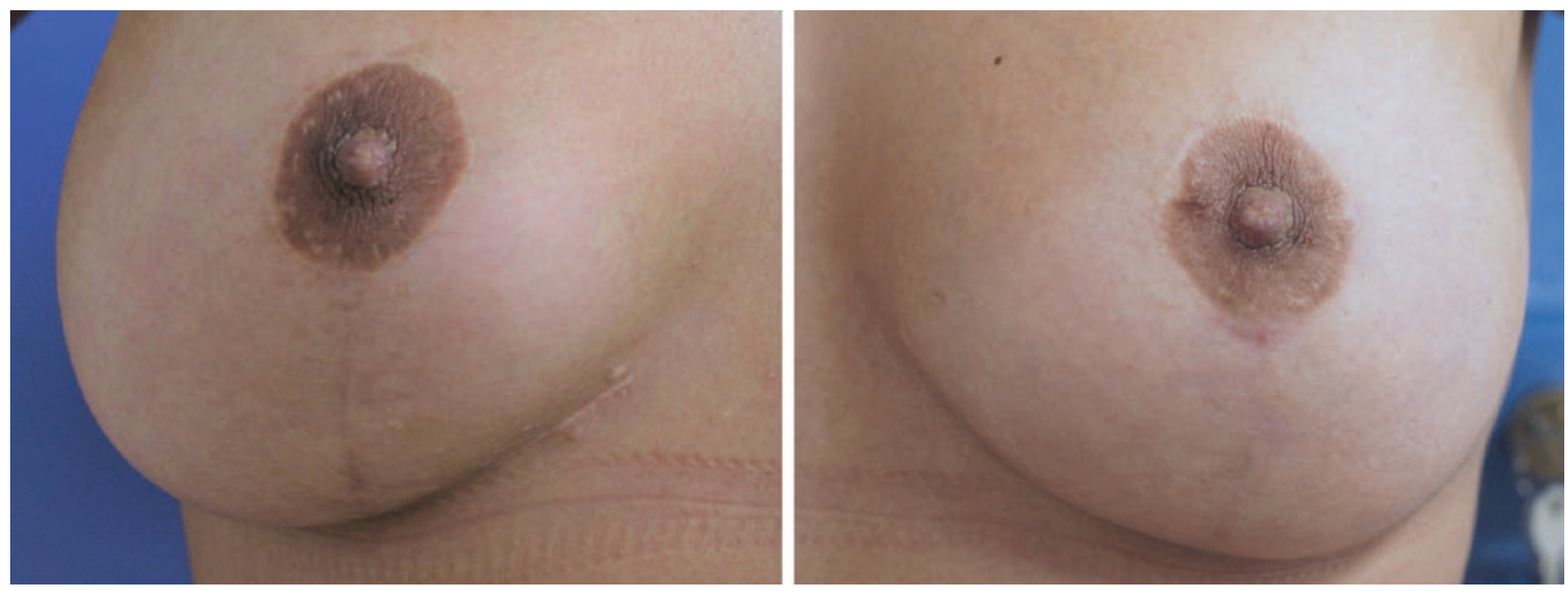

- Fig. 59.6 Enlarged photographs of periareolar and vertical scars, 12 months post-surgery 
augmentation operations [12], breast plasty, ptosis cure, prosthesis repair, abdominoplasty, brachioplasty, body lift, or gynecomastia, without any particular complication. The laser procedure takes a minimum amount of time (a few minutes, depending on the length of the scars), and I agree with the surgeons of the "SLASH" study who have judged the portable laser very easy to use. Indeed, the absence of parameter setting or adjustment really simplifies this type of procedure.

I always explain the limits of the procedure to my patients during the consultation prior to the surgery and laser treatment, in order to clear unrealistic expectations. Consequently, till today, none of my laser-treated patients were dissatisfied and their testimonials, collected in postoperative consultation or on my medical office's website, are all very positive. While this laser treatment can potentially be offered to all my patients, at the beginning I mainly proposed this procedure to patients with skin at risk or anxious by the scar result of their future operation, but now, it often happens that patients arrive at consultation demanding for it. The contraindications of the use of the laser 1210-nm laser diode UrgoTouch ${ }^{\circledR}$ are available in the manufacturer's instruction for use.

\section{Reflective Questions}

- Are there predetermining factors and risk for abnormal scarring?

- What are the guidelines for prevention and treatment of surgical scars and laser treatment?

- What are the contraindications for laser treatment?

- What is the position of laser procedure in your scar prevention strategies?

- How long does a laser treatment take? What formation is required for laser use?

\section{- Take-Home Messages}

- Different strategies have been identified to minimize the aesthetic impact of surgical scars and prevention of abnormal scar formation should always be a first priority.

- The performance and safety of the automated, portable, 1210-nm laser diode UrgoTouch ${ }^{\circledR}$ treatment reported in real-life practice are consistent with the ones established in the randomised controlled trial SLASH.

- An early and unique laser-treatment session with UrgoTouch ${ }^{\circledR}$ significantly improves the cosmetic aspect of the surgical scars.

- Patients treated with the laser procedure expressed their satisfaction both at short-term and long-term follow-up visits.

\section{References}

1. Rinker B, Veneracion M, Walsh CP. Breast ptosis: causes and cure. Ann Plast Surg. 2010;64(5):579-84.

2. Di Summa PG, Oranges CM, Watfa W, Sapino G, Keller N, Tay SK, Chew BK, Schaefer DJ, Raffoul W. Systematic review of outcomes and complications in nonimplant-based mastopexy surgery. J Plast Reconstr Aesthet Surg. 2019;72(2):243-72.

3. Celebiler O, Sönmez A, Erdim M, Yaman M, Numanoglu A. Patients' and surgeons' perspectives on the scar components after inferior pedicle breast reduction surgery. Plast Reconstr Surg. 2005;116(2):459-64.

4. Godwin Y, Barron EJ, Edmunds MC, Meyer M, Bardsley A, Logan AM, O'Neill TJ, Wood SH. A comparison of the patient and surgeon opinion on the long-term aesthetic outcome of reduction mammaplasty: have we improved over 15 years? J Plast Reconstr Aesthet Surg. 2014;67(7):932-8.

5. Gold MH, McGuire M, Mustoe TA, Pusic A, Sachdev M, Waibel J, Murcia C. International Advisory Panel on Scar Management. Updated international clinical recommendations on scar management: part 2-algorithms for scar prevention and treatment. Dermatol Surg. 2014;40(8):825-31.

6. Meaume S, Le Pillouer-Prost A, Richert B, Roseeuw D, Vadoud J. Management of scars: updated practical guidelines and use of silicones. Eur J Dermatol. 2014;24(4):435-43.

7. Monstrey S, Middelkoop E, Vranckx JJ, Bassetto F, Ziegler UE, Meaume S, Téot L. Updated scar management practical guidelines: non-invasive and invasive measures. J Plast Reconstr Aesthet Surg. 2014;67(8):1017-25.

8. Le Fourn B, Boagaert P. Secondary surgical and medical treatment of scars [Traitement secondaire chirurgical et médicales des cicatrices]. Ann Chir Plast Esthet. 2019; https://doi. org/10.1016/j.anplas.2019.07.013.

9. Capon AC, Gossé AR, Iarmarcovai GN, Cornil AH, Mordon SR. Scar prevention by laser-assisted scar healing (LASH): a pilot study using an 810-nm diode-laser system. Lasers Surg Med. 2008;40(7):443-5.

10. Souil E, Capon A, Mordon S, Dinh-Xuan AT, Polla BS, Bachelet M. Treatment with $815-\mathrm{nm}$ diode laser induces long-lasting expression of $72-\mathrm{kDa}$ heat shock protein in normal rat skin. $\mathrm{Br} \mathrm{J}$ Dermatol. 2001;144(2):260-6.

11. Casanova D, Alliez A, Baptista C, Gonelli D, Lemdjadi Z, Bohbot S. A 1-year follow-up of post-operative scars after the use of a 1210-nm laser-assisted skin healing (LASH) technology: a randomized controlled trial. Aesthet Plast Surg. 2017;41(4):938-48.

12. Hunsinger V, et al. Minimally invasive inframammary breast augmentation (MINIBA). Accepted for publication in the 2019 December issue in Plastic and Reconstructive Surgery. 
Open Access This chapter is licensed under the terms of the Creative Commons Attribution 4.0 International License (http://creativecommons. org/licenses/by/4.0/), which permits use, sharing, adaptation, distribution and reproduction in any medium or format, as long as you give appropriate credit to the original author(s) and the source, provide a link to the Creative Commons license and indicate if changes were made.

The images or other third party material in this chapter are included in the chapter's Creative Commons license, unless indicated otherwise in a credit line to the material. If material is not included in the chapter's Creative Commons license and your intended use is not permitted by statutory regulation or exceeds the permitted use, you will need to obtain permission directly from the copyright holder. 